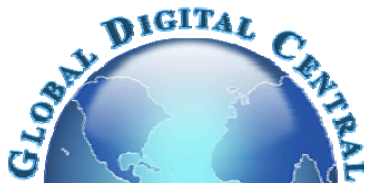

\title{
HEAT TRANSFER MEASUREMENTS FOR FLOW OF NANOFLUIDS IN MICROCHANNELS USING TEMPERATURE NANO-SENSORS
}

\author{
Jiwon Yu ${ }^{\mathrm{a}}$, Seok-Won Kang ${ }^{\mathrm{a}}$, Saeil Jeon ${ }^{\mathrm{b}}$, and Debjyoti Banerjee ${ }^{\mathrm{a}, *}$ \\ ${ }^{a}$ Department of Mechanical Engineering, Texas A\&M University, College Station, Texas, 77843-3123, USA \\ ${ }^{b}$ Technical Lead, Materials, Volvo Technology Center, Greensboro, North Carolina, 26115, USA (formerly PhD student at Texas A\&M)
}

\begin{abstract}
Experiments were performed to study the forced convective heat transfer of de-ionized water (DI water) and aqueous nanofluids in a microchannel and temperature measurements were obtained using an array of nanosensors (i.e., thin film thermocouples or "TFT"). Heat flux values were calculated from the experimental measurements for temperature recorded by the TFT array. The experiments were performed for the different test fluids where the flow rate, mass concentration (of silica nanoparticles $\sim 10-30 \mathrm{~nm}$ diameter) in the colloidal suspension and the wall temperature profile (as well as applied heat flux values) were varied parametrically.

Anomalous enhancement of the convective heat flux values were observed for the different experimental conditions. Precipitation of nanoparticles on heat exchanging surfaces was confirmed using materials characterization techniques such as Scanning Electron Microscopy (SEM) and Energy Dispersive X-Ray spectroscopy (EDX). It is suggested that moderate precipitation of nanoparticles lead to formation of isolated nanofins which cause the observed enhancements in forced convective heat transfer (due to increase in the effective surface area), while excessive precipitation results in scaling (fouling) of the surface which causes degradation of the heat flux values (compared to that of the pure solvent). This study shows that the surface conditions play a dominant role in determining the efficacy for heat transfer in multi-phase flows - particularly those involving nanoparticle coatings and nanoparticle suspensions (compared to the bulk properties of the test fluid itself).
\end{abstract}

Keywords: EDX, Microchannel,nanofin, nanoparticle, nanosensor, SEM

\section{INTRODUCTION}

Progress in micro/ nanotechnologies (MNT) have facilitated rapid integration of electric circuits and development of various commercial platforms. These applications include lap-on-chip (e.g., polymerase chain reaction or "PCR" for medical diagnostics), high temperature fuel cells, advanced manufacturing (using laser diodes), and high density microelectronic circuits. However, the operational efficacies of these platforms require close tolerance for operating temperatures along with high cooling loads (and often, high power densities within small form factors). For example, increased power dissipation and the existence of hot spots (regions with anomalously high temperature fluctuations due to elevated levels of power concentration) in computer chips and laser diodes can cause device failure (Mahajan et al., 2002). Also, advanced energy storage systems such as lithium batteries must be maintained within defined operating temperatures to avoid damage and also to avoid risk of explosions (Baker 2008; Hadjipaschalis et al., 2009). Forced convective heat transfer in microchannels using liquids (single phase or multi-phase flows, with or without phase change) is considered to be an attractive approach for cooling devices with compact form factors - because it is a cheap and effective technique. Nevertheless, forced convection involving single phase flows are often insufficient to meet cooling loads that are required to maintain various devices and systems at their operating temperature (unless the design space allows for huge pressure penalties that are associated with the high heat flux that can be achieved in small microchannels).
Stable and well dispersed colloidal suspensions of unagglomerated nanoparticles (usually at minute concentrations) are termed as nanofluids. The literature is replete with controversial reports on the anomalous enhancement of thermal conductivity of nanofluids. E.g., effective thermal conductivity of ethylene glycol was enhanced by $40 \%$ when mixed with $\mathrm{Cu}$ nanoparticles at $0.3 \%$ by volume (Eastman et al., 2001). Lee et al. (1999) reported substantial enhancements in thermal conductivity of nanofluids doped with oxide nanoparticles $\left(\mathrm{Al}_{2} \mathrm{O}_{3}\right.$, and $\mathrm{CuO}$ ). Also, Xie et al., (2003) demonstrated $\sim 10-20 \%$ enhancement of effective thermal conductivities of CNT suspensions in distilled water and ethylene glycol.

Jang and Choi (2006) reported that cooling performance of a microchannel heat sink was enhanced by approximately $10 \%$ when nanofluids were used as the test fluid. In addition, convective heat transfer coefficient of CNT nanofluids $(0.5 \%$ mass concentration) was reported to be enhanced by over $\sim 350 \%$ compared to that of the base fluid at $\operatorname{Re}=800$ (Ding et al., 2006).

The precipitation of nanoparticles on heat exchanging surfaces were shown in previous studies to form nanoscale protrusions (i.e., nanofins) which lead to enhancement of the effective area for heat transfer and resulted in enhancement of the forced convective heat flux by $\sim 10 \%$ (Nelson et al., 2009). Hence, it was hypothesized that the surface conditions play a more dominant role in forced convection heat transfer for nanofluids than their bulk properties. However, the effect and role of those nanofins on transport phenomena has not been investigated in sufficient detail in the literature.

Accurate and fast measurements of temperature profiles in the near-wall region are needed to accurately characterize the thermal

\footnotetext{
*Corresponding author.Email: dbanerjee@tamu.edu
} 
behavior of nanofluids in forced convective heat transfer. Temperature profiles can be measured by direct contact sensors (e.g., thermocouples, thermistors, etc.) or by non-intrusive techniques (e.g., using infrared or "IR" cameras). Wire-bead thermocouples are popular in heat transfer research due to their wide operating range $\left(\sim 1700{ }^{\circ} \mathrm{C}\right)$, ease of fabrication as well as ease of integration into conventional testing apparatus. However, conventional wire-bead type thermocouples (or thermistors) have a propensity to disturb flow behavior - especially for flows inside microchannels (since the size of the sensors are an impediment relative to the size of the microchannels). IR cameras are limited by the low resolution and low speed for data acquisition.

Thin Film Thermocouples (TFT) were developed using micro/ nanofabrication techniques as an alternative temperature sensing platform (Marshall et al., 1966; Golan et al., 2003; Fujiki, 2007; Kumar and Kasiviswanathan, 2009). Typical thin films deposition techniques (such as using Physical Vapor Deposition or "PVD") involve deposition thicknesses ranging from $\sim 10-500 \mathrm{~nm}$ and the TFT arrays are designed for thickness of $\sim 200-250 \mathrm{~nm}$. Hence, the incorporation of TFT within microchannels is expected to cause minimal disturbance to the flow profile while providing an accurate estimate for the near-wall temperature profile. In addition, the miniaturization of the sensors renders a very small thermal inertia - which enables data acquisition of temperature with high spatial density, high spatial resolution $(\sim 10-50$ microns pitch, $\sim 200 \mathrm{~nm}$ thickness, $\sim 10$ microns width) and at highspeeds ( 1-10 MHz) (Heichal et al., 2005). Hence, TFT arrays were used in this study to measure the wall temperature of the microchannel.

This aim of this study is to characterize the forced convective heat transfer in rectangular microchannels heated from below (insulated on the other sides) and using three different test fluids. The test fluids are de-ionized (DI) water and aqueous nanofluids (colloidal suspension of silica nanoparticles with $\sim 10-30 \mathrm{~nm}$ diameters with mass concentrations of $0.05 \%$ and $0.1 \%$ ). The goal of this study is to compare the thermofluidic behavior of aqueous nanofluids with that of the pure solvent (i.e., DI water). Temperature nano-sensors (TFT) were integrated into the experimental apparatus to measure the wall temperature profile in the axial direction (flow direction). The experiments were performed by parametrically varying the experimental parameters such as mass concentration of nanoparticles $(0.05 \%$ and $0.1 \%$ mass concentration), flow rate of the test fluids $(10 \mu \mathrm{l} / \mathrm{min}, 20 \mu \mathrm{l} / \mathrm{min}$, and $30 \mu \mathrm{l} / \mathrm{min})$, and wall temperature profile - and the wall heat flux (corresponding to wall temperature of $45^{\circ} \mathrm{C}, 55^{\circ} \mathrm{C}$, and $70{ }^{\circ} \mathrm{C}$ ).

\section{EXPERIMENTAL APPARATUS}

Syringe pump (Pump 11 Pico Plus, Harvard Apparatus) was used to provide constant flow rates in the microchannel ranging from $5-9$ $\mu \mathrm{l} / \mathrm{min}$. Polymer tubing with $400 \mu \mathrm{m}$ inner diameter (PM-1073, IDEX Health \& Science) was used to connect the inlet of the microchannel to the syringe pump. Uniform heat flux is imposed on the bottom surface of the microchannel by placing it on a copper block which is heated by embedded cartridge heaters. Temperature signals from each junction of the TFT array are recorded using an automated high speed data acquisition apparatus (NI-DAQ system, NI SCXI-1303, National Instrument) (DAQ) with a sampling rate of $200 \mathrm{~Hz}$ using LABVIEW ${ }^{\circledR}$ control software. A diagram for entire experimental setup including syringe pump, TFT array, PDMS microchannel, and DAQ system are shown in

Fig. 1. The fabrication and assembly of the experimental apparatus involves strategies borrowed from the Micro Electro Mechanical Systems (MEMS) literature - such as photolithography, soft lithography, Physical Vapor Deposition (PVD) of metals/ alloys and "lift-off" technique. Microchannels were fabricated in substrates composed of Polydimethylsiloxane (PDMS) - using soft lithography technique. The fabrication protocols (especially for the TFT array and microchannel) are described in the following sub-sections.

\subsection{Fabrication of Thin Film Thermocouple (TFT) Array}

In this study, K-type TFT array was fabricated on a 3-inch diameter silicon wafer and was used to measure the axial temperature gradient on the heat exchanging surface (bottom surface) of the microchannel. Ktype thermocouples consist of chromel (90\% nickel and $10 \%$ chromium) and alumel (95\% nickel, $2 \%$ manganese, $2 \%$ aluminum and $1 \%$ silicon) as the positive and negative electrodes, respectively. $\mathrm{K}$-type thermocouple was selected for their strong oxidation (as well as corrosion) resistance and can be used for a wide operating temperature range (varying from $0{ }^{\circ} \mathrm{C} \sim 1000{ }^{\circ} \mathrm{C}$ ).

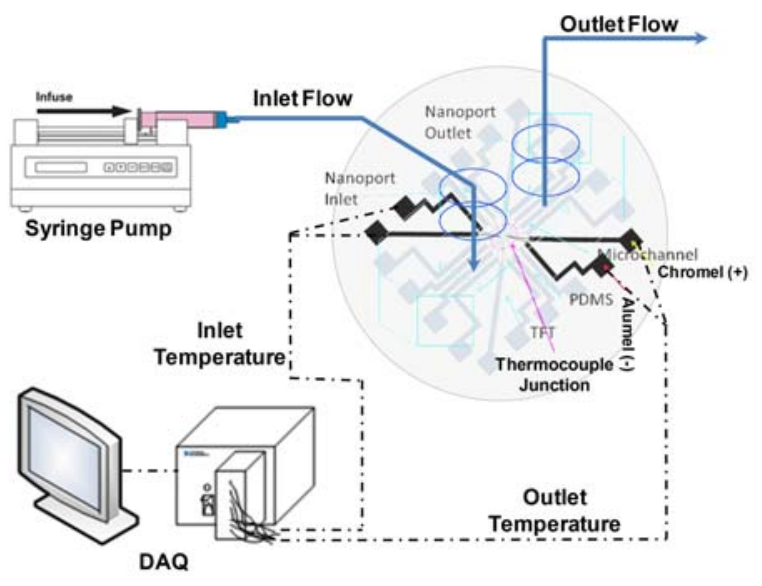

Fig. 1 Schematic of the experimental apparatus.

The TFT array was fabricated using photolithography and PVD process as shown in Fig. 2. The pattern transfer for the desired layout for the chromel or alumel layer on the silicon wafer was performed using photolithography and optical masks. The silicon wafer was initially immersed for 10 minutes in piranha solution, which is a mixture of sulfuric acid $\left(\mathrm{H}_{2} \mathrm{SO}_{4}\right)$ and hydrogen peroxide $\left(\mathrm{H}_{2} \mathrm{O}_{2}\right)$ at a ratio of $2: 1$. The piranha solution removes any organic particles or residues and is used for cleaning the silicon wafers. The silicon wafer is then rinsed with DI water five times and dried using a nitrogen gun. The cleaned silicon wafer is spin coated with positive photoresist (AZ$5412)$ at $3000 \mathrm{rpm}$ for 30 seconds and soft-baked at $110{ }^{\circ} \mathrm{C}$ for 3 minutes. The coated silicon wafer is exposed to ultra-violet (UV) light for 20 seconds using illumination intensity of $7.85 \mathrm{~mW} / \mathrm{cm}^{2}$ and through a set of photo-masks (with the desired pattern for either the chromel or the alumel layer). The exposed pattern is treated using a developer solution (MF-312, MicroChem), cleaned with DI water, and dried using a nitrogen gun. The post-bake process is performed at 120 ${ }^{\circ} \mathrm{C}$ for 30 minutes to enhance the mechanical strength of the pattern and for removing moisture on the silicon wafer.

After photolithography process, chromel or alumel are deposited on the desired pattern using the PVD process. An adhesion layer of Titanium (with $25 \mathrm{~nm}$ thickness) is deposited initially. Either chromel or alumel is then deposited immediately upto a thickness of $\sim 250 \mathrm{~nm}$. The wafer is then immersed into PG remover solution for removing the photoresist and the undesired residues on the silicon wafer (this is called the "lift-off" process in the MEMS literature). The desired pattern with chromel or alumel layer is obtained on the silicon wafer. The two layers (Chromel and Alumel) overlap at desired locations to form the thermocouple junctions (where the temperature is measured). Each TFT in the array is connected to the DAQ system by wire-bonding.

\subsection{Fabrication of Microchannel}

PDMS has a propensity to readily bond irreversibly with glass and silicon substrates (by hydrogen bonding with the native oxide layer on these substrates) which enables the prevention of any leakage of the test liquid during the experiments. To fabricate the microchannels - a mold 
is created initially. The mold is made on a separate susbstrate (e.g., another silicon wafer) using a negative photoresist (SU-8 2050, Manufactuer: MicroChem Inc.). The manufacturer specification for photolithography of SU-8 was implemented to obtain the desired shape of the microchannel mold. The designed height of the SU-8 photoresist (and microchannel) is $80 \mu \mathrm{m}$. For molding the PDMS, Sylgard 184 kit (Manufacturer: Dow Corning) was used and mixed with the curing agent at a volumetric ratio of 10:1. Bubbles are eliminated from the mixture by placing it in a vacuum chamber for more than 30 minutes. The bubble free PDMS mixture is poured on the prepared mold. Two nanoports (Upchurch Scientific, N-126S) are placed and supported using crocodile clip on the mold prior to pouring the PDMS mixture. These nanoports serve as the inlet and outlet ports of the microchannel, as shown in Fig. 3 (a). The poured PDMS is then cured at $150{ }^{\circ} \mathrm{C}$ for 10 minutes. After cooling the cured PDMS to room temperature, PDMS is carefully peeled off from the silicon wafer mold and cut to appropriate size using a razor blade. The PDMS substrate is then pressed onto the silicon wafer (with the TFT array fabricated in-situ) to form the microchannel with the inlet and outlet ports. Images of the fabricated microchannel and integrated experimental setup are shown in Fig. 3. The dimensions of the microchannel are $24 \mathrm{~mm}$ in length, $1 \mathrm{~mm}$ in width, and $74 \mu \mathrm{m}$ in height.

\section{Chromel \\ Alumel}

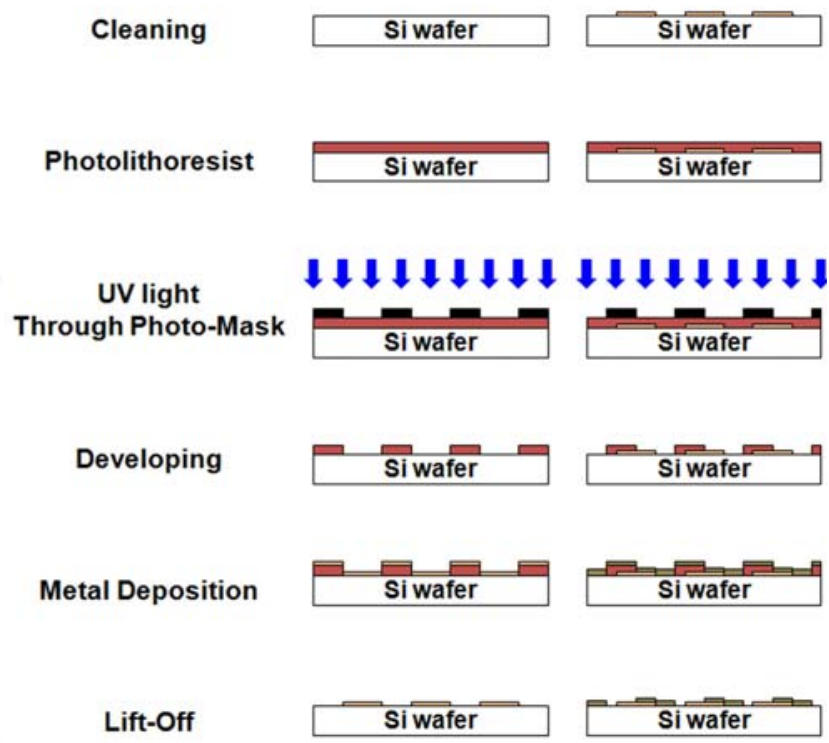

Fig. 2 Schematic showing the fabrication protocol for the TFT array.

\section{MODELING AND ANALYSIS}

\subsection{Modeling of Flows in the Microchannel}

Heat flux from heat exchanging surface to the test fluids (i.e. DI water or aqueous nanofluids) is calculated using a two-dimensional (2-D) analytical model. This assumption is justified since the aspect ratio for the rectangular cross section of the microchannel is $\sim 250$. Similarly the aspect ratio of the rectangular cross section of the microchannel in the axial direction (in the flow direction) exceeds $\sim 500$. As a result the entrance effects can be neglected. PDMS has a very low thermal conductivity $(0.15 \mathrm{~W} / \mathrm{m}-\mathrm{K})$, therefore the top surface of the PDMS microchannel is assumed to be insulated. Uniform heat flux condition is assumed to exist at the bottom wall of the microchannel due to the higher thermal mass of the heated copper block on which the microchannel is assembled. The effect of gravity (and body forces) can be neglected for microchannel geometries without any loss of accuracy.
Hence this can be treated as hydraulically and thermally fully developed laminar flow between two infinite parallel flat plates with uniform heat flux at the bottom plate and insulated boundary condition for the top plate (with constant thermo-physical properties and neglecting the body force terms).

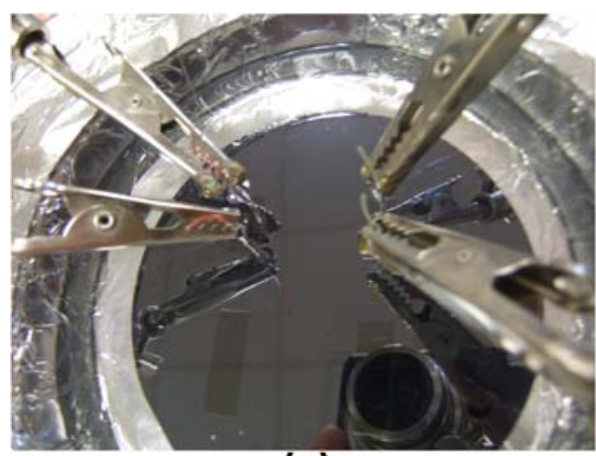

(a)

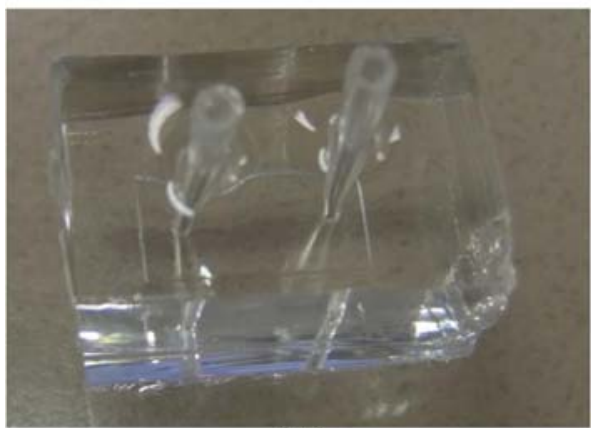

(b)

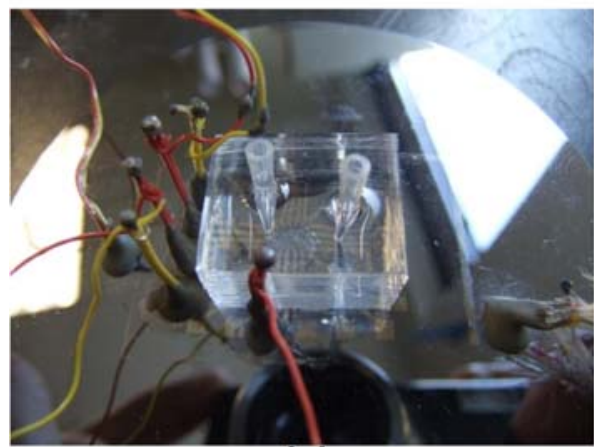

(c)

Fig. 3 Images of: (a) Liquid PDMS poured on the mold and with nanoports supported using crocodile clips; (b) fabricated PDMS microchannel with nanoports (for input and output ports); and (c) PDMS microchannel integrated with TFT array.

\subsection{Analysis of Heat Transfer Rate}

Therefore, the heat transfer from the bottom wall to the coolant (DI water and aqueous nanofluids) flowing through the control volume can be calculated using a 2-D model as shown in Fig. 4. Energy balance for the control volume and calculation of heat transfer coefficient is performed as follows (Jung et al., 2010; Jeon et al., 2010, Kang et al., 2011; Jung and Banerjee, 2011):

$$
\begin{aligned}
& q_{w}^{\prime \prime} \cdot w \cdot d x=\frac{\partial}{\partial x}\left(\rho \bar{u} A c_{p} T_{b}\right) d x \\
& q_{w}^{\prime \prime}=2 \rho \bar{u} H c_{p} \frac{\partial T_{b}}{\partial x} \approx 2 \rho \bar{u} H c_{p} \frac{\Delta T_{b}}{\Delta x} \\
& h=q_{w}^{\prime \prime} /\left(T_{w}-\frac{T_{\text {out }}+T_{\text {in }}}{2}\right)
\end{aligned}
$$




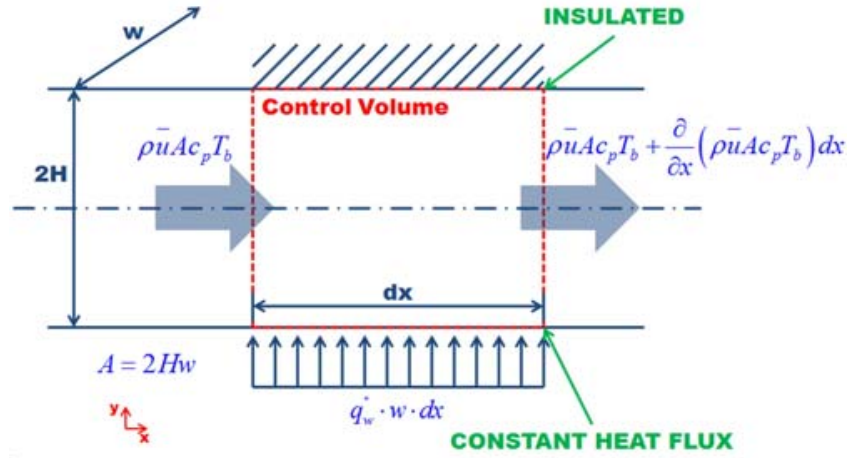

Fig. 4 Schematic showing control volume analysis for microchannel.

The mass averaged (mean) velocity is calculated using the flow rate of the syringe pump and cross-sectional area of the microchannel. Density of the nanofluids and the base fluid are assumed to be the same, since the mass fraction of the nanoparticles is small. However, careful evaluation of the other thermophysical properties for the nanofluids is required (e.g., specific heat capacity, viscosity and thermal conductivity). Literature reports show that even at minute concentration nanoparticles the specific heat capacity, thermal conductivity and viscosity values can change drastically. For example, it is reported that the specific heat capacity of water decreases when $\mathrm{Al}_{2} \mathrm{O}_{3}$ nanoparticles are added (Zhou and $\mathrm{Ni}, 2008$ ). Specific heat capacity of nanofluid samples (60:40 ethylene glycol and water) were also reported to decrease by $12 \%$ when $\mathrm{SiO}_{2}$ nanoparticles were added at $10 \%$ concentration (Namburu et al., 2007). For non-aqueous solvents the specific heat capacity was reported to be enhanced dramatically at minute concentration of nanoparticles. Shin and Banerjee (2010, 2011a, $2011 \mathrm{~b}$ ) reported enhancement of the specific heat capacity of nanofluids by $\sim 20-120 \%$ when silica $\left(\mathrm{SiO}_{2}\right)$ nanoparticles were dispersed in an eutectic mixture of liquid (molten) salts consisting of lithium carbonate + potassium carbonate (62:38 molar ratio) and chloride salt eutectics.

\subsection{Measurement Uncertainty}

The measurement uncertainty for the temperature in the copper block is $\pm 1{ }^{\circ} \mathrm{C}$. The uncertainty in heat flux was evaluated using the method of Kline and McClintock (1953):

$$
\frac{\omega_{q}}{q}=\left[\left(\frac{\omega_{k}}{k}\right)^{2}+\left(\frac{\omega_{T_{1}}}{T_{2}-T_{1}}\right)^{2}+\left(\frac{\omega_{T_{2}}}{T_{2}-T_{1}}\right)^{2}+\left(\frac{\omega_{\Delta x}}{\Delta x}\right)^{2}\right]^{\frac{1}{2}}
$$

The measurement uncertainty for the surface temperature for the TFT array can be estimated from various sources. The data acquisition system (32 bit resolution) has a precision error of $\pm 0.005{ }^{\circ} \mathrm{C}$ for the temperature range used in this experiment. During the experiments in this study, the range ( 3 times the standard deviation) of temperature fluctuations at steady state conditions was measured to be $\pm 0.05{ }^{\circ} \mathrm{C}$. Therefore the total uncertainty of the temperature measurement was approximated to be $\pm 0.055{ }^{\circ} \mathrm{C}$. The uncertainty for thermal conductivity for copper is assumed to be $\pm 1.0 \%$ and the uncertainty in the location of two thermocouples is estimated to be $\pm 5.0 \%$. Therefore, the maximum uncertainty for the surface heat flux (i.e., at the minimum heat flux value) is estimated as $\pm 15 \%$.

\section{RESULTS AND DISCUSSIONS}

Based on the temperature measurements recorded by the TFT array Fig. 5 and Fig. 6 were plotted to calculate the wall temperature gradients during the flow of $\mathrm{SiO}_{2}$ nanofluids (at $0.05 \%$ and $0.1 \%$ mass concentrations), respectively. As mentioned earlier, the specific heat capacity values of aqueous solvents are degraded when nanoparticles are added. Vijjha and Das (2009) reported experimental data for aqueous nanofluids and suggested a correlation for the specific heat capacity variation with temperature and concentration of the nanoparticles. As reported in this study, there is a degradation of specific heat capacity at low temperatures. Surprisingly, a marginal enhancement in the specific heat capacity of silica nanofluilds (over that of pure water) was reported in this study at higher temperatures (approximately $>70{ }^{\circ} \mathrm{C}$ ). Suggested correlations and fitting coefficients from this study are presented in Eq. (5) and Table 1.

$$
\frac{C_{p n f}}{C_{p b f}}=\frac{\left((A T)+B\left(\frac{C_{p s}}{C_{p b f}}\right)\right)}{(C+\phi)}
$$

Table 1 Values of coefficients used in Eq. (5) for calculating specific heat capacity of silica $\left(\mathrm{SiO}_{2}\right)$ nanofluids

\begin{tabular}{ccccc}
\hline A & B & C & $\begin{array}{c}\text { Maximum } \\
\text { Error [\%] }\end{array}$ & $\begin{array}{c}\text { Average } \\
\text { Absolute error } \\
{[\%]}\end{array}$ \\
\hline 0.001769 & 1.1937 & 0.8021 & 3.1 & 1.5 \\
\hline
\end{tabular}

Eq. (5) is valid over the temperature $(T)$ range from $315 \mathrm{~K}$ to 363 $\mathrm{K}$ and volumetric concentrations $(\phi)$ ranging from $0 \%$ to $10 \%$. Also, literature reports show that the specific heat capacity of nanoparticles (pure metals, oxides, and zeolites) is higher than those of the bulk materials (Tan et al., 2009). The specific heat capacity values of $\mathrm{SiO}_{2}$ nanoparticles are enhanced by $\sim 5-10 \%$ (Tan et al., 2009) compared to the bulk properties. In this study, specific heat capacity of silica nanoparticles $\left(\mathrm{C}_{p s}\right)$ is considered to be $819.5 \mathrm{~J} / \mathrm{kg} \cdot \mathrm{K}$ which is $10 \%$ higher value than the specific heat of bulk $\mathrm{SiO}_{2}$ (which is $745 \mathrm{~J} / \mathrm{kg} \cdot \mathrm{K}$ ). The specific heat capacity of DI water, $\mathrm{C}_{p b f}=4182 \mathrm{~J} / \mathrm{kg} \cdot \mathrm{K}$. Using these thermal properties, the magnitude of heat flux from the heat exchanging surface (bottom wall of the microchannel) during the flow of $\mathrm{SiO}_{2}$ nanofluids with mass concentrations at $0.05 \%$ and $0.1 \%$ are calculated using Eq. (2).

Table 2 Enhancement of convective heat transfer as a function of flow rate and wall temperature for nanofluids containing $\mathrm{SiO}_{2}$ nanoparticles with mass concentrations of $0.05 \%$ and $0.1 \%$

\begin{tabular}{cccc}
\hline $\mathrm{T}_{\mathrm{w}}\left[{ }^{\circ} \mathrm{C}\right]$ & $\begin{array}{c}\text { Flow Rate } \\
{[\mu \mathrm{l} / \mathrm{min}]}\end{array}$ & $\begin{array}{c}0.05 \% \mathrm{SiO}_{2} \\
\text { Nanofluid }\end{array}$ & $\begin{array}{c}0.1 \% \mathrm{SiO}_{2} \\
\text { Nanofluid }\end{array}$ \\
\hline \multirow{2}{*}{45} & 10 & $139.5 \%$ & $21.2 \%$ \\
& 20 & $129.9 \%$ & $58.5 \%$ \\
\hline \multirow{2}{*}{55} & 30 & $74.5 \%$ & $41.6 \%$ \\
\hline & 10 & $-31.5 \%$ & $-6.9 \%$ \\
& 20 & $-23.8 \%$ & $-5.1 \%$ \\
& 30 & $-27.1 \%$ & $-2.1 \%$ \\
\hline \multirow{2}{*}{70} & 10 & $-40.9 \%$ & $-6.2 \%$ \\
& 20 & $-28.2 \%$ & $-3.7 \%$ \\
& 30 & $-12.9 \%$ & $-11.3 \%$ \\
\hline
\end{tabular}

The calculated values of heat flux during flow of nanofluids are compared to that for DI water, and are plotted in Fig. 7 as well as listed in Table 2. Table 2 shows that the heat flux is significantly enhanced by the nanofluids at the lower temperature $\left(\sim 45^{\circ} \mathrm{C}\right)$. The enhancement ranges from $\sim 40-140 \%$ depending on the concentration of the nanoparticles and the flow rate. Although significant enhancement was observed at low wall temperatures $\left(\mathrm{T}_{\mathrm{w}} \approx 45{ }^{\circ} \mathrm{C}\right)$, degradation of convective heat transfer was observed at higher wall temperatures $\left(\mathrm{T}_{\mathrm{w}} \approx\right.$ $55{ }^{\circ} \mathrm{C}$ and $\mathrm{T}_{\mathrm{w}} \approx 70{ }^{\circ} \mathrm{C}$ ). Nelson et al. (2009) suggested that the 
anomalous enhancements are caused by the precipitation of nanoparticles on the heat exchanging surfaces resulting in formation of nanoscale protrusions on the wafer surface. The silicon wafer is originally perfectly smooth (i.e., to atomic scale roughness since it is a single crystal of silicon with exposed $<100>$ crystal plane). These nanoscale protrusions (or roughness) enhance the effective surface area available for heat transfer - thus behaving like a nanofin. It is remarkable that nanofluids at lower concentration $(0.05 \%)$ showed much higher enhancement $(139.5 \%)$ than at higher mass concentration $(0.1 \%)$, where the enhancement was only $21 \sim 58 \%$. This result demonstrates that although precipitation of nanoparticles on heat exchanging surface forms nanofins and increases heat removal rate,

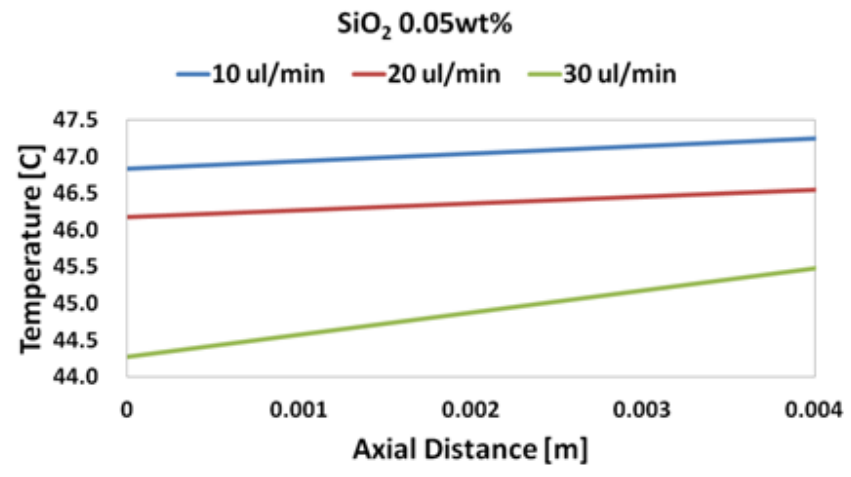

(a)

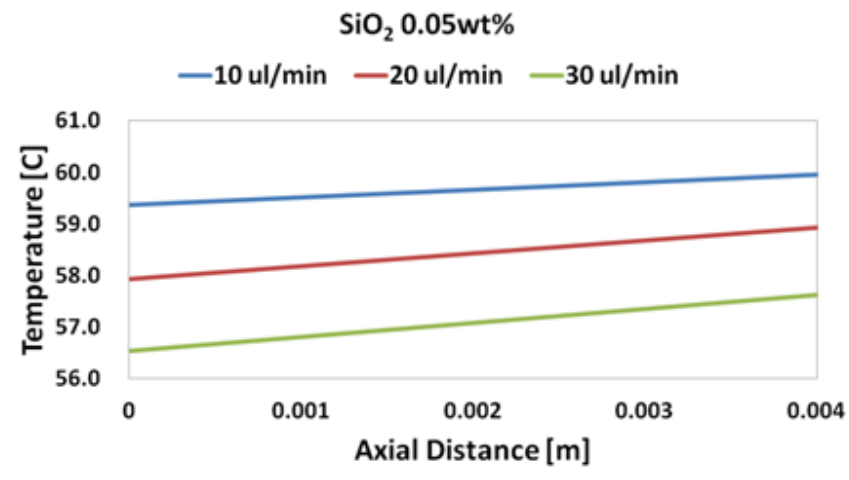

(b)

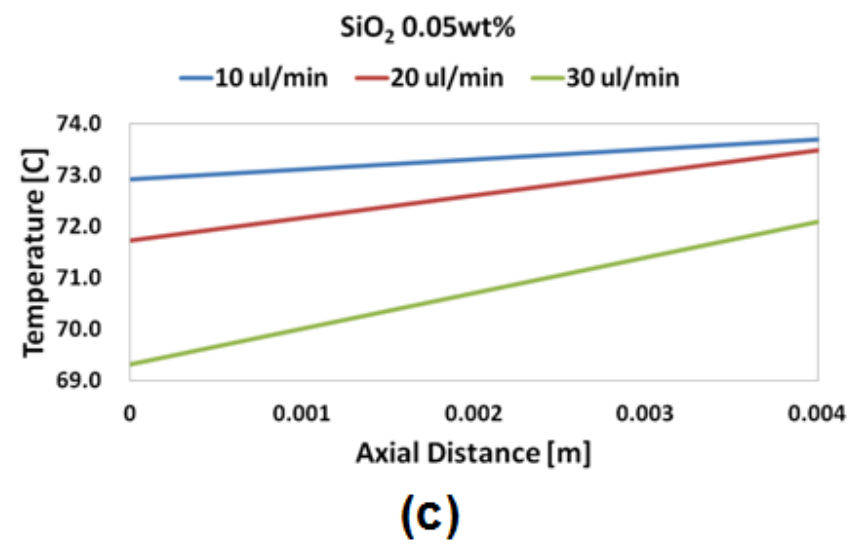

Fig. 5 Wall temperature profile recorded using TFT array during flow of $\mathrm{SiO}_{2}$ nanofluid at $0.05 \%$ mass concentration for wall temperature: (a) $\mathrm{T}_{\mathrm{w}} \approx 45^{\circ} \mathrm{C}$, (b) $\mathrm{T}_{\mathrm{w}} \approx 55^{\circ} \mathrm{C}$, and (c) $\mathrm{T}_{\mathrm{w}} \approx 70^{\circ} \mathrm{C}$. excessive precipitation possibly leads to partial scaling (or fouling) of the heat exchanging surface as well as of the flow conduits - which causes degradation of the resulting heat transfer. Convective heat transfer coefficients were calculated using Eq. (3) and listed in Table 3. Furthermore, whereas the range of Reynolds number the current study is very small $(\mathrm{Re}=0.2 \sim 0.5)$, other studies focused on measurement of heat transfer of nanofluids were performed for higher values of Reynolds number $(\operatorname{Re} \sim 14$ or higher).

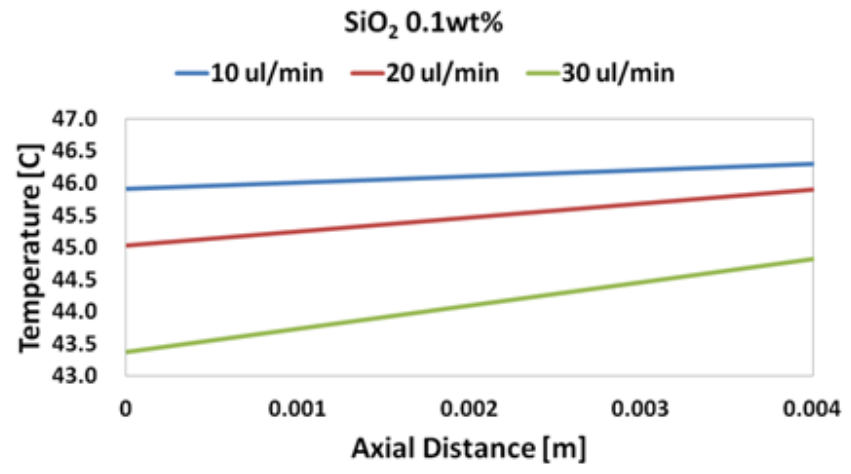

(a)

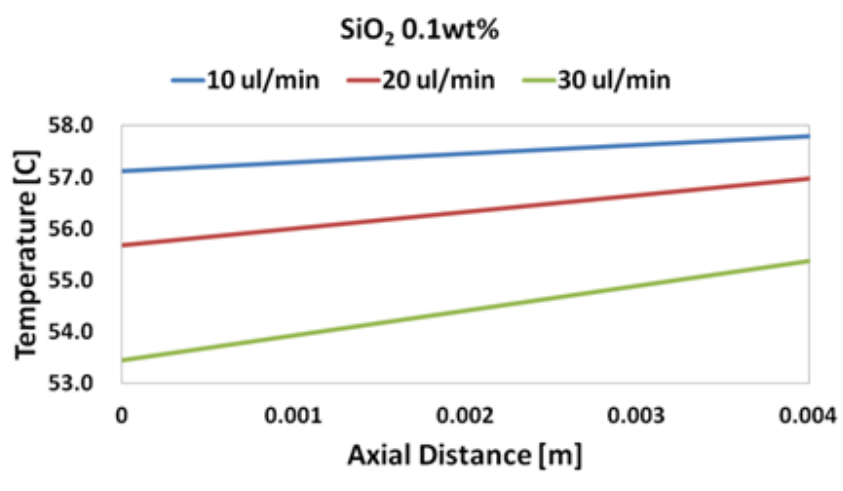

(b)

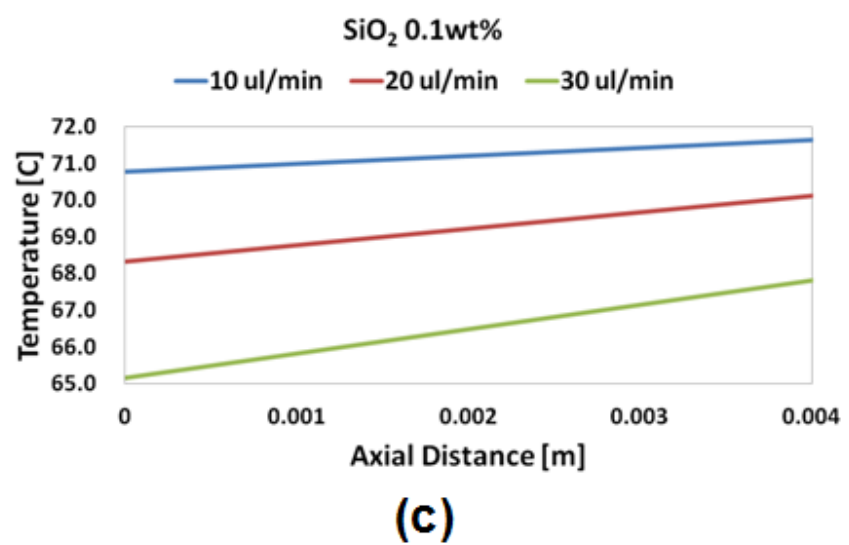

Fig. 6 Wall temperature profile recorded using TFT array during flow of $\mathrm{SiO}_{2}$ nanofluid at $0.1 \%$ mass concentration for wall temperature: (a) $\mathrm{T}_{\mathrm{w}} \approx 45^{\circ} \mathrm{C}$, (b) $\mathrm{T}_{\mathrm{w}} \approx 55^{\circ} \mathrm{C}$, and (c) $\mathrm{T}_{\mathrm{w}} \approx 70^{\circ} \mathrm{C}$. 


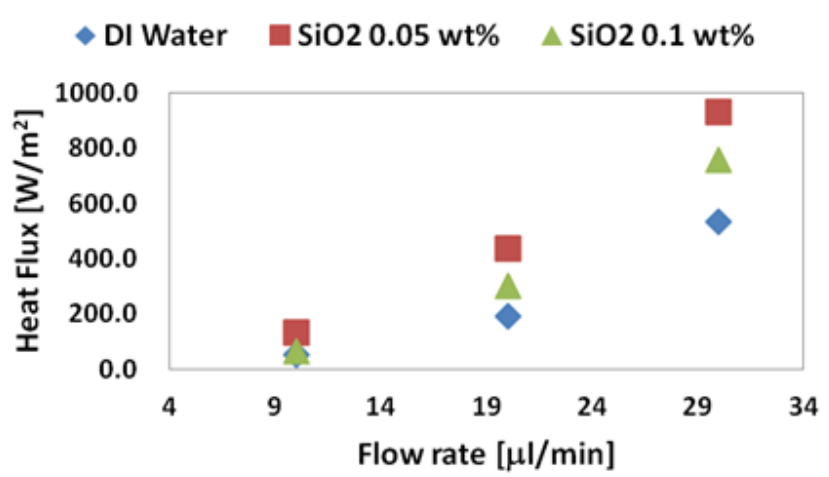

(a)

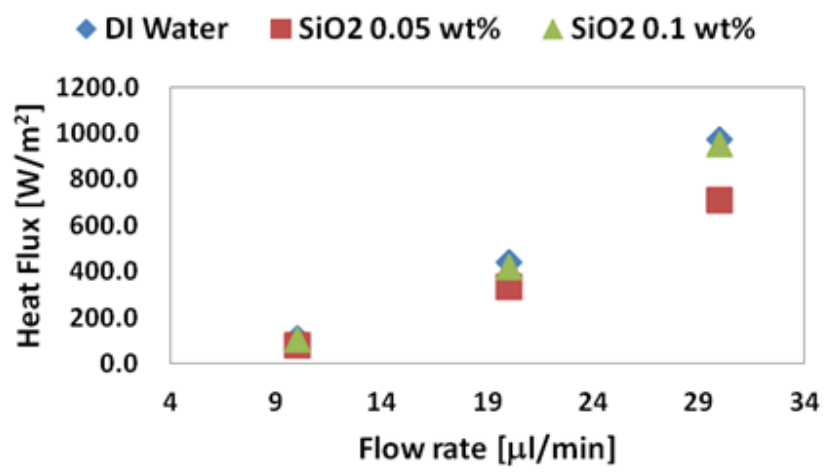

(b)

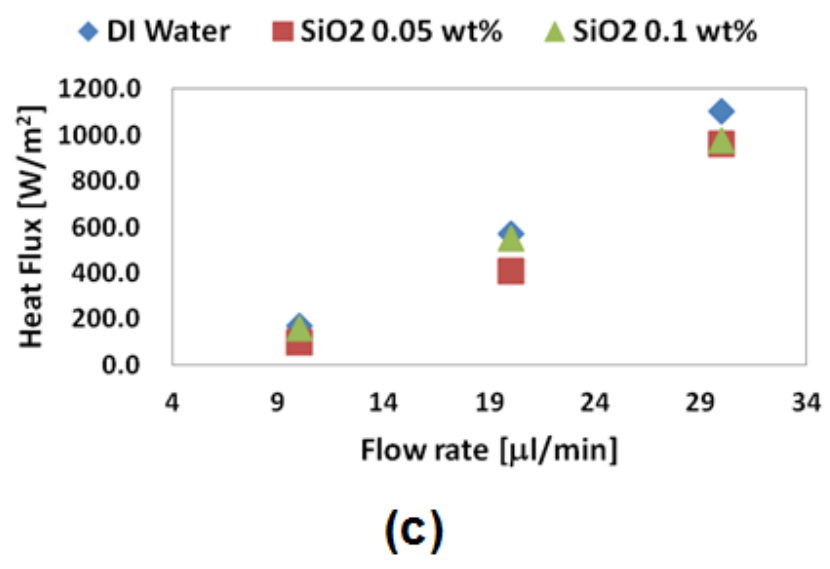

Fig. 7 Heat flux as a function of flow rate for: (a) $\mathrm{T}_{\mathrm{w}} \approx 45^{\circ} \mathrm{C}$, (b) $\mathrm{T}_{\mathrm{w}} \approx$ $55^{\circ} \mathrm{C}$, and (c) $\mathrm{T}_{\mathrm{w}} \approx 70^{\circ} \mathrm{C}$.

Convective heat transfer coefficient for flow of $\mathrm{Al}_{2} \mathrm{O}_{3}$ nanofluids in microchannels at $\mathrm{Re}=60$ and $\mathrm{Re}=200$ were reported to be approximately 1000 (Jung et al., 2009) and 7000 9000 (Lee and Mudawar, 2007), respectively. Hence, these two reports show that the value of heat transfer coefficient drops as Re decreases. Therefore, it can be expected that the experimental observations obtained from the current study would be significantly smaller compared to the results reported in the literature. Measurement of temperatures at inlet and outlet ports also provide an estimate for the heat flux values (however there is greater experimental uncertainly in this technique since the temperature rise is relatively "small" between the inlet and outlet ports), as shown in the following equation:

$$
q_{w}^{\prime \prime}=\frac{\dot{m} c_{p}\left(T_{o u t}-T_{\text {in }}\right)}{A}
$$

Table 4 shows the comparison of the calculations from both Eq. (2) and Eq. (6). Additionally the experimental uncertainty can be exacerbated when the thermocouples are embedded at the inlet and outlet ports, since the flow is possibly disturbed due to the presence of the thermocouples which could also influence the results. Also, the tips of each thermocouple are significantly larger (in comparison to the cross section of the microchannels); thus, leading to additional experimental uncertainties. For these reasons, the calculated values of heat flux using Eq. (2) and Eq. (6) are not always consistent - as shown in Table 4.

Table 3 Convective heat transfer coefficients $\left[\mathrm{W} / \mathrm{m}^{2} \mathrm{~K}\right]$ for all cases

\begin{tabular}{ccccc}
\hline $\mathrm{T}_{\mathrm{w}}\left[{ }^{\circ} \mathrm{C}\right]$ & $\begin{array}{c}\text { Flow Rate } \\
{[\mathrm{ml} / \mathrm{min}]}\end{array}$ & DI Water & $\begin{array}{c}0.05 \% \mathrm{SiO}_{2} \\
\text { Nanofluid }\end{array}$ & $\begin{array}{c}0.1 \% \mathrm{SiO}_{2} \\
\text { Nanofluid }\end{array}$ \\
\hline \multirow{3}{*}{45} & 10 & 2.8 & 6.0 & 3.5 \\
& 20 & 9.3 & 20.2 & 17.1 \\
& 30 & 29.9 & 47.1 & 49.2 \\
\hline \multirow{2}{*}{55} & 10 & 4.0 & 2.5 & 3.8 \\
& 20 & 17.0 & 11.9 & 17.0 \\
& 30 & 40.0 & 27.6 & 42.3 \\
\hline \multirow{2}{*}{70} & 10 & 4.4 & 2.5 & 4.2 \\
& 20 & 16.9 & 11.1 & 16.4 \\
& 30 & 36.7 & 29.7 & 33.4 \\
\hline
\end{tabular}

Table 4 Compare of heat flux values $\left[\mathrm{W} / \mathrm{m}^{2} \mathrm{~K}\right]$ calculated by using Eq. (2) and Eq. (6)

\begin{tabular}{cccccccc}
\hline \multirow{2}{*}{$\begin{array}{c}\mathrm{T}_{\mathrm{w}} \\
{\left[{ }^{\circ} \mathrm{C}\right]}\end{array}$} & $\begin{array}{c}\text { Flow } \\
\text { Rate } \\
{[\mu \mathrm{l} / \mathrm{min}]}\end{array}$ & \multicolumn{2}{c}{$\mathrm{q}_{\mathrm{DIw}}$} & \multicolumn{2}{c}{$\mathrm{q}_{\mathrm{SiO} 2} 0.05 \mathrm{wt} \%$} & \multicolumn{2}{c}{$\mathrm{q}_{\mathrm{SiO} 2} 0.1 \mathrm{wt} \%$} \\
\cline { 3 - 8 } 45 & 10 & 55 & 179 & 131 & 183 & 66 & 212 \\
& 20 & 191 & 268 & 438 & 464 & 302 & 576 \\
& 30 & 535 & 731 & 934 & 952 & 758 & 1100 \\
\hline \multirow{3}{*}{55} & 10 & 112 & 162 & 76 & 148 & 104 & 212 \\
& 20 & 439 & 496 & 335 & 440 & 417 & 693 \\
& 30 & 972 & 897 & 709 & 942 & 951 & 1255 \\
\hline \multirow{3}{*}{70} & 10 & 168 & 157 & 99 & 93 & 157 & 192 \\
& 20 & 569 & 712 & 408 & 552 & 548 & 818 \\
& 30 & 1103 & 1524 & 960 & 1315 & 978 & 1666 \\
\hline
\end{tabular}

To confirm the observations (similar to that of Nelson et al., 2009), SEM images of the heat exchanging surfaces were obtained in this study. These SEM images for the different surfaces and corresponding to the different experimental conditions are shown in Fig. 8 and Fig. 9. These images were obtained after completion of the experiments that involved the flow of nanofluids containing $\mathrm{SiO}_{2}$ at $0.1 \%$ mass concentration. Precipitated nanoparticles were detected on the TFT arrays - as well as at locations away from the TFT arrays.

Materials characterization was performed to evaluate the nature of the precipitates. Energy Dispersive X-Ray (EDX) spectroscopy was performed to verify that the chemical composition of the precipitated particles do indeed correspond to that of the $\mathrm{SiO}_{2}$ nanoparticles. EDX measurements are plotted in Fig. 10. 


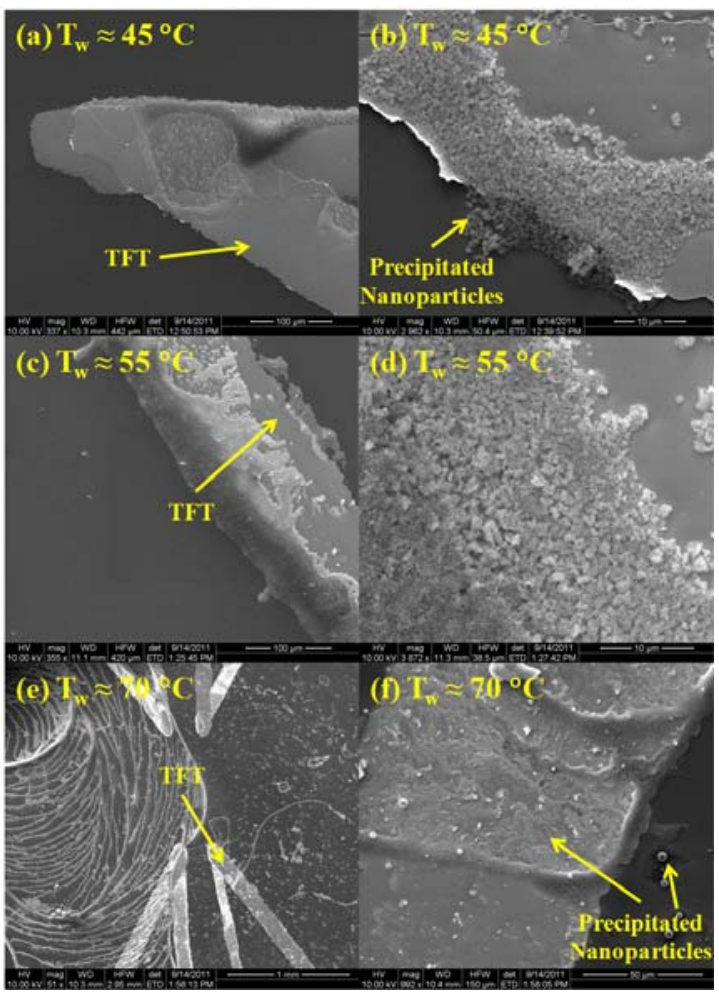

Fig. 8 SEM images of nanoparticle precipitates on the bottom surface of the microchannel (at the location of the TFT array) - after performing forced convective heat transfer experiments using silica nanofluids.

The distinct peaks corresponding to $\mathrm{Si}$ and $\mathrm{O}$ in Fig. 10 confirm that the other impurities are not present in the precipitated particles. Nickel peak detected in Fig. 10 (a) is due to the TFT (both chromel and alumel) which contain more than $90 \%$ nickel. According to Fig. 8 and Fig. 9 the agglomerated nanoparticle precipitates are $\sim 200-700 \mathrm{~nm}$ diameter. The precipitation is observed to occur in isolated regions with sufficient spacing between the precipitates (at $\mathrm{T}_{\mathrm{w}} \approx 45^{\circ} \mathrm{C}$ ). These SEM results are in good agreement with the results reported by Nelson et al. (2009). Hence, the isolated precipitates act as nanofins and enhance heat transfer by increasing the effective surface area for heat exchange between the hot surface and the coolant. However, particle precipitation is much more severe at higher wall temperatures as shown in Fig. 8 and Fig. 9.

After performing the experiments, the surface of the substrates were also scanned using Lateral Force Microscopy (LFM), which is a technique often used in Atomic Force Microscopy (AFM). This measurement is used to obtain an estimate for the surface roughness of smooth substrates (and therefore shows the size and shape of the surface nano-structures). The results from the LFM measurements are shown in Fig. 11. Fig. 11 (a) shows the formation of nanofins, while Figs. 11 (b) and (c) show that a film has been deposited over the substrates (rather than nanofins). This result is in good agreement with SEM analysis, discussed earlier.

This leads to greater surface coverage of the heat exchanging surface by the precipitates - causing scaling (or fouling) and thus leading to higher thermal resistance for heat transfer between the silicon wafer surface and the working fluids. Thus, heat transfer rates are degraded when scaling occurs. It is presumed that the reason why excessive precipitation occurs at high heat fluxes (high average wall temperature) is the longer time of contact for the nanofluids with the heated surfaces, during progression to steady state conditions. It required 2 hours to reach steady state conditions (i.e., temperature fluctuations were less than $\pm 0.05^{\circ} \mathrm{C}$ ) at $\mathrm{T}_{\mathrm{w}} \approx 45^{\circ} \mathrm{C}$.

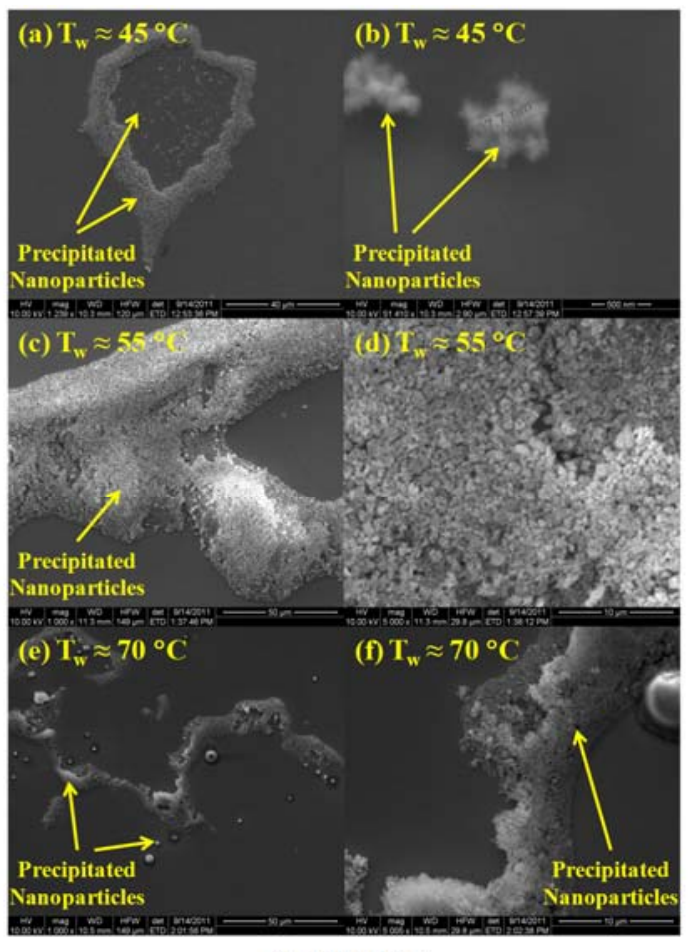

Away TFT

Fig. 9 SEM images of nanoparticle precipitates on the bottom surface of the microchannel (at locations away from TFT array) - after performing forced convective heat transfer experiments using silica nanofluids.

Subsequent experiments resulted in cumulative contact time for the substrates with the nanofluids, where the contact time is estimated to be $\sim 4$ hours and $\sim 6$ hours, to reach steady state at $\mathrm{T}_{\mathrm{w}} \approx 55^{\circ} \mathrm{C}$ and $\mathrm{T}_{\mathrm{w}}$ $\approx 70{ }^{\circ} \mathrm{C}$, respectively. Since these substrates are exposed to enhanced precipitation (due to longer time in contact with the nanofluids for the experiments performed at at $\mathrm{T}_{\mathrm{w}} \approx 55{ }^{\circ} \mathrm{C}$ and $\mathrm{T}_{\mathrm{w}} \approx 70{ }^{\circ} \mathrm{C}$ ), particle precipitation is also more rampant leading to greater surface coverage by the precipitated nanoparticles and degradation in heat transfer (since silica fouling has lower thermal conductivity than the exposed silicon substrate). In addition, increase in concentration of nanoparticles also accelerates the precipitation and agglomeration of nanoparticles, which results in inferior rates of convective heat transfer for these nanofluids.

Surprisingly, the level of degradation disappeared at higher values of wall temperature and mass concentration of nanoparticles. Vajjha and Das (2009) reported that for aqueous silica nanofluids - the specific heat capacity exceeded that of pure water for temperatures $70{ }^{\circ} \mathrm{C}$. Hence, at this temperature the higher specific heat capacity values result in higher convective heat transfer -which compensates for the lower conduction heat transfer due to surface fouling from the agglomerated silica nanoparticle precipitates.

Hence, these results suggest that the amount of precipitation of the nanoparticles can lead to different levels of modification of the surface topologies which can cause either increase or decrease in the rate of cooling. This precipitation is a function of the mass concentration, the exposure (contact) time and other material parameters (e.g., specific heat as a function of temperature) as well as surface interactions. 


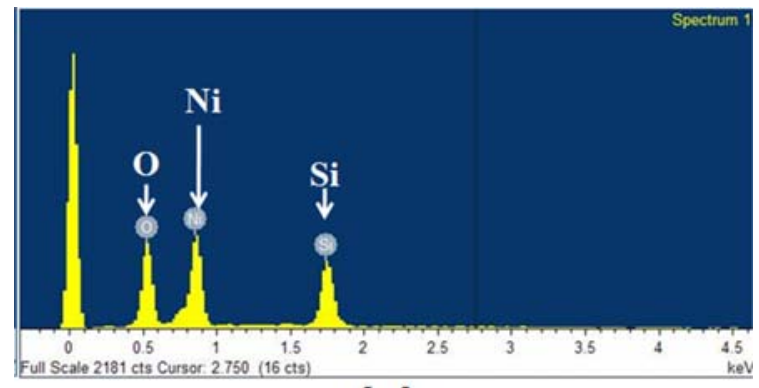

(a)

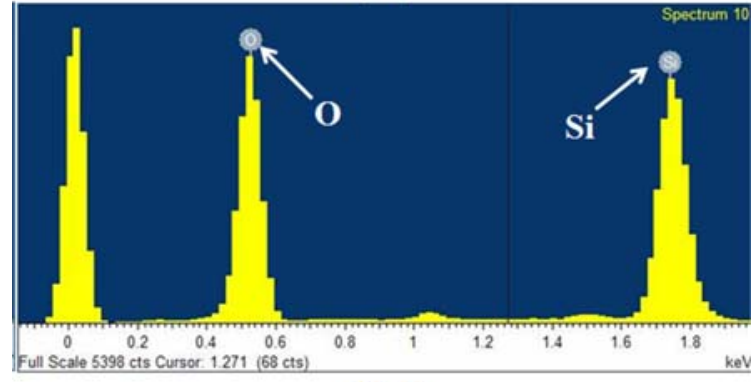

(b)

Fig. 10 Materials characterization using Energy Dispersive X-Ray (EDX) spectroscopy of the precipitates on the bottom wall of the microchannel: (a) In regions at the location of the TFT array; and (b) away from the location of the TFT array. The Ni peak in (a) confirms the presence of the TFT array (which is composed of alloys with more than $90 \% \mathrm{Ni}$ ).
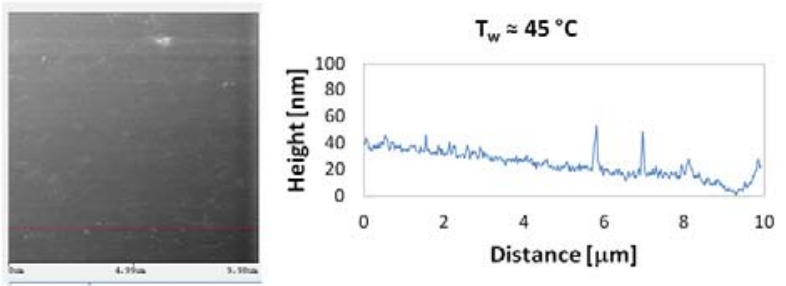

(a)
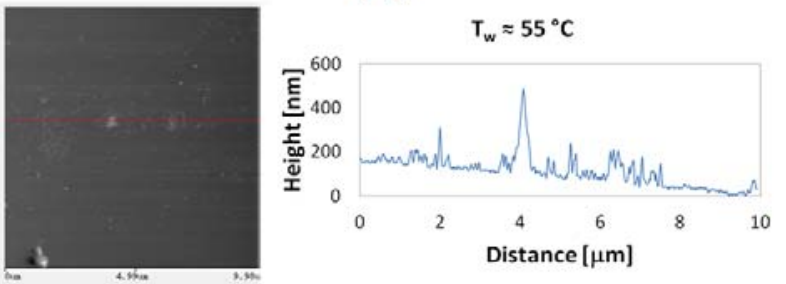

(b)
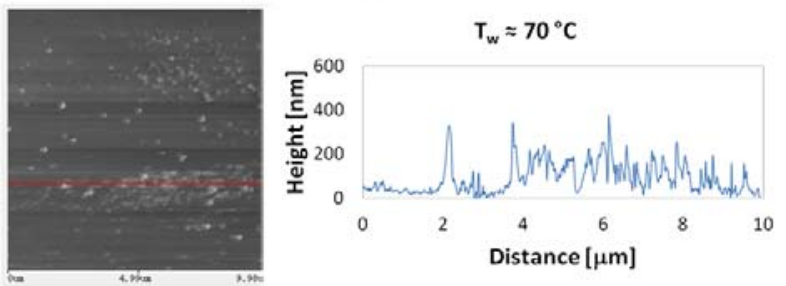

(c)

Fig. $11 \mathrm{LFM}$ images and line analysis results for (a) $\mathrm{T}_{\mathrm{w}} \approx 45^{\circ} \mathrm{C}$, (b) $\mathrm{T}_{\mathrm{w}}$ $\approx 55^{\circ} \mathrm{C}$, and (c) $\mathrm{T}_{\mathrm{w}} \approx 70{ }^{\circ} \mathrm{C}$.

\section{CONCLUSIONS}

In this experimental study the effect of surface modification of heat exchanging surfaces due to the isolated precipitation of nanoparticles on the forced convective heat transfer of silica nanofluids in the rectangular microchannel was explored. The results from this study can be summarized as follows:

1. Enhancement of the forced convective heat flux for flow of nanofluids in a microchannel was observed at low wall temperatures $\left(\sim 45^{\circ} \mathrm{C}\right)$ over that of pure water. The enhancements were observed to be higher for lower concentration of the nanoparticles. Materials characterization (using SEM and EDX) was also performed to verify the morphology of the precipitated nanoparticles. The images show that at lower temperatures the isolated precipitation of nanoparticles leads to formation of nanofins which enhance the surface area for heat transfer and thereby enhances the resulting heat flux values.

2. Degradation of heat transfer occurred at higher operating temperatures $\left(\mathrm{T}_{\mathrm{w}} \approx 55{ }^{\circ} \mathrm{C}\right.$ and $\left.\mathrm{T}_{\mathrm{w}} \approx 70{ }^{\circ} \mathrm{C}\right)$ due to the excessive precipitation of silica nanoparticles. Scaling (fouling) of the heat exchanging surfaces due to extensive precipitation of the nanoparticles causes degradation of the resulting heat flux.

3. At temperatures exceeding $70{ }^{\circ} \mathrm{C}$, the nanofluids have a higher specific heat capacity than DI water. This can cause the level of degradation of the heat flux values to be lower than that at $55^{\circ} \mathrm{C}$. Hence, competing effects between thermal properties of nanofluids and the nanofin effect can lead to anomalous behavior for forced convective heat flux from heated microchannels to nanofluid coolants.

4. The exposure time for the nanofluids and the wall temperature are expected to control the level of precipitation of the nanoparticles.

\section{NOMENCLATURE}

$A$

$c_{p}$

$c_{p b f}$

$c_{p n f}$

$c_{p s}$

$H$

$h$

$k$

$q^{\prime \prime}$

$\operatorname{Re}$

$T_{f}$

$T_{\text {in }}$

$T_{\text {out }}$

$T_{w}$

$\bar{u}$

$w$

$x$

Greek Symbols

$\rho$
$\omega$
$\phi$

\section{Subscripts}

$b$

w area of the bottom surface of microchannel $\left(\mathrm{m}^{2}\right)$ specific heat capacity $(\mathrm{J} / \mathrm{kg} \cdot \mathrm{K})$ specific heat capacity of base fluid - water $(\mathrm{J} / \mathrm{kg} \cdot \mathrm{K})$ specific heat of capacity nanofluid $(\mathrm{J} / \mathrm{kg} \cdot \mathrm{K})$ specific heat capacity of nanoparticle $(\mathrm{J} / \mathrm{kg} \cdot \mathrm{K})$ half of the height of the microchannel $(\mathrm{m})$ convective heat transfer coefficient $\left(\mathrm{W} / \mathrm{m}^{2} \cdot \mathrm{K}\right)$ thermal conductivity $(\mathrm{W} / \mathrm{m} \cdot \mathrm{K})$ heat flux $\left(\mathrm{W} / \mathrm{m}^{2}\right)$ Reynolds number mean temperature of fluid $(\mathrm{K})$ inlet temperature of fluid (K) outlet temperature of fluid $(\mathrm{K})$ surface temperature $(\mathrm{K})$ mass averaged (mean) velocity $(\mathrm{m} / \mathrm{s})$ width of a microchannel (m) coordinate $(\mathrm{m})$

\author{
density $\left(\mathrm{kg} / \mathrm{m}^{3}\right)$ \\ standard deviation \\ volumetric mass concentration
}

bulk (mean) temperature wall, heat exchanging surface 


\section{ACKNOWLEDGEMENTS}

This work was supported by a research grant from the Qatar National Research Foundation (QNRF).We also thank Ms. Alina DattaGupta (student of A\&M Consolidated High School, College Station, TX) for her help with analyzing the experimental data.

\section{REFERENCES}

Baker, J., 2008, "New technology and possible advances in energy storage," Energy Policy, 36(12), 4368-4373.

http://dx.doi.org/10.1016/j.enpol.2008.09.040

Ding, Y., Alias, H., Wen, D., and Williams, R. A., 2006, "Heat transfer of aqueous suspensions of carbon nanotubes (CNT nanofluids)," International Journal of Heat and Mass Transfer, 49(1-2), 240-250. http://dx.doi.org/10.1016/j.ijheatmasstransfer.2005.07.009

Eastman, J. A., Choi, S. U. S., Li, S., Yu, W., and Thompson, L. J., 2001, "Anomalously increased effective thermal conductivities of ethylene glycol-based nanofluids containing copper nanoparticles," Applied Physics Letters, 78(6), 718-720.

http://dx.doi.org/10.1063/1.1341218

Fujiki, H., 2007, "New thin-film multijunction thermal converter design for improved high-frequency performance," IEEE Sensors Journal, 7(9), 1243-1247.

http://dx.doi.org/10.1109/JSEN.2007.897966

Golan, G., Axelevitch, A., Sigalov, B., and Gorenstein, B., 2003, "Integrated thin film heater-thermocouple systems," Microelectronics Reliability , 43(3) 509-512.

http://dx.doi.org/10.1016/S0026-2714(02)00320-7

Hadjipaschalis, I., Poullikkas, A., and Efthimiou, V., 2009, "Overview of current and future energy storage technologies for electric power applications," Renewable and Sustainable Energy Reviews, 13(6-7), 1513-1522.

http://dx.doi.org/10.1016/j.rser.2008.09.028

Heichal, Y., Chandra, S., and Bordatchev, E., 2005, "A fast-response thin film thermocouple to measure rapid surface temperature changes," Experimental Thermal and Fluid Science, 30(2), 153-159. http://dx.doi.org/10.1016/i.expthermflusci.2005.05.004

Jang, S. P., and Choi, S. U. S., 2006, "Cooling performance of a microchannel heat sink with nanofluids," Applied Thermal Engineering, 26(17-18), 2457-2463.

http://dx.doi.org/10.1016/j.applthermaleng.2006.02.036

Jeon, S., Kang, S., and Banerjee, D., "Investigation of Thermal Characteristics of Nanofluids during Flow in a Micro-channel using an Array of Surface Temperature-nano-sensors", Paper No. SAE-10PSC0135, SAE Power Systems Conference, November 2-4, Fort Worth, Texas, 2010.

Jung, J., and Kwak, H., 2009, "Forced convective heat transfer of nanofluids in microchannels," International Journal of Heat and Mass Transfer,52(1-2),466-472.

http://dx.doi.org/10.1016/j.ijheatmasstransfer.2008.03.033

Jung, S., and Banerjee, D., 2011, "A simple analytical model for specific heat of nanofluid with tube shaped and disc shaped nanoparticles", Paper No. AJTEC2011-44372, ASME/JSME 8th Thermal Engineering Joint Conference, Honolulu, Hawaii, March 1317.

Jung, S., Jo, B., Shin, D., and Banerjee, D., "Experimental Validation of a Simple Analytical Model for Specific Heat Capacity of Aqueous Nanofluids", Paper No. SAE-10PSC-0134, SAE Power Systems Conference, November 2-4, Fort Worth, Texas, 2010.
Kang, S., Jeon, S., and Banerjee, D., 2011, "Experimental Study of Thermal Performance of Nanofluids During Flow in Microchannels using Surface Temperature-Nano-Sensors", Paper No. AJTEC201144374, ASME/JSME 8th Thermal Engineering Joint Conference, Honolulu, Hawaii, March 13-17.

Kline, S. J., and McClintock, F. A., 1953, "Describing uncertainties in SingleSample experiments," Mechanical Engineering, 75(1), 38.

Kumar, S. R. S., and Kasiviswanathan, S., 2009, "Transparent ITOMn:ITO thin-film thermocouples," IEEE Sensors Journal, 9(7), 809-13. http://dx.doi.org/10.1109/JSEN.2009.2022556

Lee, J., and Mudawar, I., 2007, "Assessment of the effectiveness of nanofluids for single-phase and two-phase heat transfer in microchannels," International Journal of Heat and Mass Transfer, 50(3-4), 452-463.

http://dx.doi.org/10.1016/j.ijheatmasstransfer.2006.08.001

Lee, S., Choi, S. U. -., Li, S., and Eastman, J. A., 1999, "Measuring thermal conductivity of fluids containing oxide nanoparticles," Journal of Heat Transfer, 121(2), 280-289.

Mahajan, R., Nair, R., Wakharkar, V., Swan, J., Tang, J., and Vandentop, G., 2002, "Emerging directions for packaging technologies," Intel Technology Journal, (2)

Marshall, R., Atlas, L., and Putner, T., 1966, "The preparation and performance of thin film thermocouples," Journal of Scientific Instruments, 43(3), 144-149.

http://dx.doi.org/10.1088/0950-7671/43/3/305

Namburu, P. K., Kulkarni, D. P., Dandekar, A., and Das, D. K., 2007, "Experimental investigation of viscosity and specific heat of silicon dioxide nanofluids," Micro and Nano Letters, 2(3), 67-71. http://dx.doi.org/10.1049/mnl:20070037

Nelson, I. C., Banerjee, D., and Ponnappan, R., 2009, "Flow loop experiments using polyalphaolefin nanofluids," Journal of Thermophysics and Heat Transfer, 23(4), 752-761. http://dx.doi.org/10.2514/1.31033

Shin, D., and Banerjee, D., 2010, "Effects of silica nanoparticles on enhancing the specific heat capacity of carbonate salt eutectic (work in progress)", International Journal of Structural Change in Solids Mechanics and Applications, Vol. 2, No. 2, pp. 25-31, November.

Shin, D., and Banerjee, D., 2011a, "Enhanced Specific Heat of Silica Nanofluid", ASME Journal of Heat Transfer, Volume 133, Issue 2, 024501 (4 pages), February. http://dx.doi.org/10.1115/1.4002600

Shin, D., and Banerjee, D., 2011b, "Enhancement of specific heat capacity of high-temperature silica-nanofluids synthesized in alkali chloride salt eutectics for solar thermal-energy storage applications," International Journal of Heat and Mass Transfer, 54(5-6), 1064-1070. http://dx.doi.org/10.1016/j.ijheatmasstransfer.2010.11.017

Vajjha, R. S., and Das, D. K., 2009, "Specific heat measurement of three nanofluids and development of new correlations," Journal of Heat Transfer, 131(7), 1-7. http://dx.doi.org/10.1115/1.3090813

Xie, H., Lee, H., Youn, W., and Choi, M., 2003, "Nanofluids containing multiwalled carbon nanotubes and their enhanced thermal conductivities," Journal of Applied Physics, 94(8), 4967-4971. http://dx.doi.org/10.1063/1.1613374

Zhou, S., and Ni, R., 2008, "Measurement of the specific heat capacity of water-based $\mathrm{Al}_{2} \mathrm{O}_{3}$ nanofluid," Applied Physics Letters, 92(9), 093123

http://dx.doi.org/10.1063/1.2890431 